\title{
DISPONIBILIZAÇÃO DO CATÁLOGO \\ DO ACERVO DAS BIBLIOTECAS DA UNICAMP NA WEB, UTILIZANDO O ALTAVISTA SEARCH INTRANET
}

\author{
Mariângela Pisoni ZANAGA \\ SISTEMAS AUTOMATIZADOS BIBLIOTECA CENTRAL - UNICAMP \\ E-mail: marian@obelix.unicamp.br \\ Izilda Morelli Pignataro da SILVA \\ CENTRO DE COMPUTAÇÃO - UNICAMP \\ e-mail: izilda@ccuec.unicamp.br
}

\section{RESUMO}

Desenvolvimento e implantação de projeto, visando a disponibilização do catálogo automatizado de monografias (livros e teses), existente nas bibliotecas da UNICAMP, na WEB, utilizando a ferramenta de busca AltaVista Search Intranet.

Palavras-chave: Catálogo automatizado; Recuperação de informações; Alta Vista Search Intranet; WEB; INTERNET.

\section{ABSTRACT}

Development and implementation of a project, applying the search engine AltaVista Search Intranet, offering the library an automated catalog of UNICAMP in the WEB.

Keywords: Catalogue automation; Information retrieval; AltaVista Search Intranet; WEB; INTERNET.

O Sistema de Bibliotecas da UNICAMP dispõe, desde 1992, de catálogo on-line, oriundo de processamento técnico automatizado de monografias, incluindo, além de livros, todas as teses defendidas na Universidade e materiais pertencentes a Coleções Especiais, abrangendo, também, obras raras.

Os dados que compõem este catálogo estão alocados em computador central da UNICAMP (IBM9021) e são acessados através do comando 'telnet' por toda comunidade interna e externa.
Apesar de oferecer vários pontos de recuperação, além dos principais: autor, título, assunto, traz dificuldades relativas ao emulador de terminal e à configuração de teclado, dentre outras.

A home page do Sistema de Bibliotecas da UNICAMP (http://www.unicamp.br/bc) foi elaborada pela Área de Sistemas Automatizados da Biblioteca Central e disponibilizada em janeiro de 1997. Naquela ocasião, através dela, era oferecido acesso, via telnet, ao banco de dados bibliográficos da Universidade - ACERVUS, 
compreendendo a base de dados de monografias e de periódicos.

O avanço da tecnologia, que traz a mudança de arquitetura de hardware, sugere o uso de plataforma cliente-servidor. Ao mesmo tempo, a INTERNET se concretiza cada vez mais no Brasil, trazendo, em curto espaço de tempo, novas ferramentas.

As bibliotecas universitárias brasileiras continuam sendo as propulsoras no emprego de tecnologias na área de informação. Sua clientela está se aperfeiçoando sempre, fazendo com que a aplicação prática da filosofia cliente-servidor e a disponibilização de informações, relativas às coleções existentes nas bibliotecas universitárias, tornem-se então uma necessidade inadiável.

Em decorrência, os profissionais bibliotecários têm também que estar sempre em sintonia com as mudanças que ocorrem em sua área de atuação. Eles devem procurar dispor de recursos que atendam as necessidades manifestas por seus usuários, fazendo com que as unidades de informação em que atuam participem de forma positiva no desenvolvimento de atividades de ensino e pesquisa.

Em estatística apresentada pelo Grupo de Trabalho de Bibliotecas Virtuais, coordenado pelo IBICT, das bibliotecas disponíveis na INTERNET, $64 \%$ delas são universitárias, sendo que os demais $36 \%$ se distribuem em especializadas, escolares, públicas e nacional (GRUPO DE TRABALHO...,1998a).

Estes dados comprovam a grande participação das bibliotecas universitárias na rede de informações e reforçam a necessidade de um envolvimento cada vez maior das mesmas, aperfeiçoando os serviços prestados.

O Grupo de Trabalho de Bibliotecas Virtuais, criado em novembro de 1996, objetiva contribuir para que bibliotecas, centros e serviços de informação do Brasil se conectem à INTERNET (GRUPO DE TRABALHO...,1998b). Tem também como preocupação o apoio X a 'iniciativas, projetos e atividades que visem a geração de metodologias, instrumentos e outros mecanismos', que busquem coletar e disponibilizar na rede a informação gerada no país.
As experiéncias desenvolvidas por diferentes tipos de bibliotecas, uma vez divulgadas, podem ser adotadas pelas demais, contribuindo para o aumento do número de sites a serem visitados.

Ao disponibilizar as informações na rede mundial de computadores, as bibliotecas estarão contribuindo para democratizar a informação. Ao mesmo tempo, facilitando o acesso à mesma, pois o ambiente gráfico, atualmente, é amplamente conhecido e bastante amigável ao usuário.

Com o objetivo de oferecer aos usuários das bibliotecas da UNICAMP e aos da comunidade externa mais um recurso a ser empregado na recuperação da informação, partiu-se para o desenvolvimento de estudos com a finalidade da escolha de um software apropriado ao ambiente da WEB, para indexar uma base de dados já existente (catálogo on-line de monografias).

Após a análise de diversos softwares, pelos analistas de sistemas do Centro de Computação da UNICAMP, foi escolhido o AltaVista Search Intranet, da Digital Corporation, pois, além de ser utilizado em aplicações na INTERNET, apresenta boa performance e oferece opções para recuperação textual.

O software AItaVista Search Intranet dispõe de muitos recursos que são aplicáveis à recuperação de informações bibliográficas. Do ponto de vista do usuário, podem-se citar: vários idiomas de diálogo, dois formatos para realização da recuperação da informação, uso de minúsculas para recuperação de palavras escritas com letras maiúsculas também, emprego de operadores distintos em cada um dos formatos, truncamento de termos a serem pesquisados, diversos formatos de apresentação do resultado da busca, ordenação do resultado por ordem decrescente de relevância (ALTAVISTA ....,1998). Oferece também recursos de indexação, que possibilitam:

- a identificação particular de cada documento indexado;

- a indexação por palavras e números existentes em qualquer posição do registro, aumentando as possibilidades de busca e recuperação de informações;

- a inclusão, atualização ou deleção de qualquer documento presente no índice. 
Após a definição do software a ser utilizado, analistas de sistemas passaram a trabalhar na geração de arquivos em formato texto, a partir da base de dados, recuperável através do software STAIRS (IBM), alocada no mainframe.

Foi utilizada a linguagem de programação COBOL para inserir diretivas, visando a formatação de páginas em HTML (HyperText Markup Language).

A linguagem de programação C-Shell foi empregada para particularizar cada documento, tornando-o individualmente disponível para consulta na INTERNET. Para exclusão e substituição de documentos alterados, recorre-se à mesma linguagem.

A base de dados preparada para o ambiente WEB foi alocada em um servidor Digital Alpha Station 200.

Depois de realizadas as definições técnicas, o projeto passou a ser desenvolvido em conjunto por analistas de sistemas do Centro de Computação e por bibliotecários da Área de Sistetnas Automatizados da Biblioteca Central, da UNICAMP.

Cada documento, correspondente a um registro bibliográfico, possui campos variados, que contêm informações específicas, tais como: autor, título, assunto, biblioteca, dentre outros. A nomenclatura destes campos foi mantida, visando facilitar a recuperação mais precisa da informação. Muitos são os campos oriundos do processamento técnico automatizado. Com a finalidade de tornar ao usuário mais fácil o acesso à informação, os campos foram selecionados e dispostos, de forma a priorizar as informações mais importantes, ao mesmo tempo em que houve mudança no nome de alguns deles.

Uma identificação do Sistema de Bibliotecas, contendo o logotipo da UNICAMP e o nome de seu banco de dados - ACERVUS, foi incluída na página principal do catálogo on-line de acesso público na WEB, recuperável através da ferramenta de busca AltaVista. A identificação é apresentada também em cada registro bibliográfico recuperado. Esta página principal foi adaptada, tendo sido inserida breve informação sobre o uso do software recuperador.
A partir de julho de 1997, tornou-se acessível na WEB a base de monografias, produto da experiência desenvolvida, aplicando-se o software AltaVista Search Intranet (http:// acervus.unicamp.br). A recuperação da informação foi agilizada, considerando-se o tempo de resposta e a facilidade que a busca na WEB oferece aos usuários. Treinamento no acesso à nova versão do catálogo de acesso público foi oferecido à equipe de profissionais das bibliotecas da UNICAMP pela Área de Sistemas Automatizados da Biblioteca Central, com base em manual elaborado para este fim (UNICAMP, 1997).

As bibliotecas disponibilizaram clientes WEB, oferecendo mais esta forma de recuperação a seus usuários, que passaram a receber instruções para uso da nova interface.

A atualização de dados, proveniente do processamento automatizado, é feita periodicamente, através da geração de novos arquivos, contendo documentos a serem incluídos, excluídos e alterados.

Conta-se atualmente com recurso que oferece dados estatísticos diários relativos ao horário da consulta, domínio e sub-domínio dos hosts que solicitaram a busca. O software utilizado para este fim foi desenvolvido pela University of California, Irvine: wwwstat. Ele processa a estatística de acessos ao servidor WWW em que estão alocados os dados disponíveis para consulta, compilando-a e apresentando-a em formato HTMI, (WWWSTAT,1998).

Através das informações estatísticas obtidas diariamente, podem se verificar os horários de maior acesso, a variação de freqüência de consulta nos diferentes dias da semana, os domínios e sub-domínios predominantes, por país.

O acesso a catálogos eletrônicos de bibliotecas e unidades de informação na WEB é uma realidade e os profissionais bibliotecários têm se envolvido nesta tarefa. As diversas experiências desenvolvidas devem embasar e incentivar instituições que ainda não dispõem suas fontes de informação na INTERNET. Este é o passo inicial, que deve ser priorizado e, posteriormente, aperfeiçoado, a partir da organização e disponibilização de fontes eletrônicas de informação em bibliotecas virtuais, possibilitando 
a consulta a textos completos (GRUPO DE TRABALHO..., 1998c).

Enquanto iniciativas neste sentido começam a ser empreendidas no Brasil, deve-se voltar a atenção para a preparação do profissional de informação, visando o acompanhamento e a ação efetiva em ambientes em mudança.

\section{REFERÊNCIAS BIBLIOGRÁFICAS}

ALTAVISTA. [On-line] Disponível: http:// www.altavista.digital.com. [09 out. 1998].

GRUPO DE TRABALHO DE BIBLIOTECAS VIRTUAIS. Bibliotecas virtuais classificadas por categoria. [On-line] Disponível: http://www.cg.org.br/gt/ gtbvlestatistica.htm. [09 out. 1998a].
GRUPODETRABALHODE BIBLIOTECAS VIRTUAIS. Objetivos. [On-line] Disponível: http:// www.cg.org.br/gt/gtbv/objetvos.htm. [09 out. 1998b].

GRUPODETRABALHODEBIBLIOTECAS VIRTUAIS. Orientações estratégicas para a implementação de bibliotecas virtuais no Brasil. [On-line] Disponível: http://www.ibict.br/cionline/docs/2629701.htm. [09 out. 1998c].

UNICAMP. Sistema de Bibliotecas. Biblioteca Central. Sistemas Automatizados. ACERVUS: Monografias (Livros/Teses): catálogo on-line de acesso público - AItaVista Search. Campinas, 1997.

WWWSTAT. HTTPd logfile analysis software. [On-line] Disponível: http://www.ics.uci.edu/pub/ websoft/wwwstat/. [09 out. 1998]. 